Article

\title{
Energy Performance Certificates-The Role of the Energy Price
}

\author{
Jon Olaf Olaussen $^{1, * \mathbb{D}}$, Are Oust ${ }^{1} \mathbb{D}$, Jan Tore Solstad ${ }^{1}$ and Lena Kristiansen ${ }^{2}$ \\ 1 NTNU Business School, Norwegian University of Science and Technology, 7491 Trondheim, Norway; \\ are.oust@ntnu.no (A.O.); jan.t.solstad@ntnu.no (J.T.S.) \\ 2 Sparebank 1 Regnskapshuset SMN, Postboks 4799 Torgaard, 7467 Trondheim, Norway; \\ lena.kristiansen@smnregnskap.no \\ * Correspondence: jon.o.olaussen@ntnu.no
}

Received: 22 August 2019; Accepted: 16 September 2019; Published: 17 September 2019

\begin{abstract}
Energy performance certificates (EPCs) were introduced to give property buyers better information about the energy efficiency of dwellings and provide incentives to make energy-efficient investments. Previous studies on the effect of EPCs on property value have yielded divergent results, with some studies finding that energy labels affect property values, but others finding that energy labels have little or no effect. The present paper takes the analysis one step further. Using data on energy prices in combination with transaction data from Oslo, we conclude that not only the energy label, but also the energy performance of dwellings in general, has little to no effect on transaction prices. This result is in line with the inferences of several survey studies, which indicate that when people buy a dwelling, they pay considerably less attention to its energy performance compared with other factors, such as the location, neighborhood, size, garden, and the number of bedrooms.
\end{abstract}

Keywords: energy performance certificates; PV energy cost; PV energy savings; house prices; environmental regulation

\section{Introduction}

In July 2010, Norway implemented the energy labeling system for houses and dwellings, and energy performance certification became fully mandatory. Since then, all houses and dwellings for sale are required to have an energy performance certificate (EPC). The motivation for using EPCs is to provide information to buyers and tenants about the energy performance of buildings. Reliable information on energy consumption is supposed to improve the functioning of real estate markets and create incentives to invest in energy efficiency. The information provided to potential buyers by the EPC is intended to stimulate energy efficiency investments because the consequent improved energy performance will potentially increase the sale prices and rents of buildings [1].

The EPC reflects the expected energy consumption of a building, which enables buyers to account for the expected current and future energy costs when assessing their willingness to pay for a residence. However, the expected energy costs are not only a function of energy consumption. Energy prices and the interest rate will also influence the energy costs, with the latter working through the discounting of future values into present values. Hence, energy performance will potentially influence the transaction prices of dwellings and houses, in combination with the influence of energy prices and the interest rate.

The empirical literature has drawn contrasting conclusions concerning the role of EPCs in energy conservation [2]. In the commercial segment, Eichholtz et al., found that US office buildings with a "green rating" sold for prices about $16 \%$ higher than did those without such ratings [3]. In a study applying hedonic regression on residential dwellings in the Netherlands, Brounen and Kok found a price premium for houses labeled as more energy efficient [4]. (A hedonic regression breaks down the 
house price into its constituent characteristics and obtains estimates of the contributory value of each characteristic.) Fuerst et al., used both hedonic and augmented repeat sales regressions, and found a significant EPC premium for dwellings sold in England [5]. In addition, a report to the European Commission concluded that EPCs have a significant effect on property prices and rents in selected European Union (EU) countries [1].

Other studies indicate that EPCs have a weak or negligible impact on transaction prices. Interestingly, Murphy investigated the case of the Netherlands, that is the same housing market as Brounen and Kok [4,6]. By applying an online questionnaire, she studied the role of the EPC in the transaction process of buildings. Contrary to Brounen and Kok, she concluded that few householders pay attention to the EPC and stated that the EPC would not have the planned impact, even if the system was fully implemented [4]. Similar surveys from the UK by Laine, and from Germany by Amecke came to the same conclusion, namely that EPCs only have a minor or negligible effect on price negotiations and investment decisions [7,8]. In a similar manner, Backhaus et al. performed in-depth interviews with homeowners in 10 European countries, as well as a large survey among homeowners in five European countries, and found that EPCs have a modest or negligible impact on homeowners' purchase decisions [9]. In a hedonic model for single family housing in Sweden, Wahlström found no price premium of EPCs, but rather a price premium for housing attributes that improve the energy efficiency [10].

Olaussen et al. carried out a statistical study resembling that of Brounen and Kok for the case of Norway [4,11]. However, they reached a similar conclusion to that of Murphy [6]. Performing a hedonic regression analysis based on housing transactions in Oslo, the capital of Norway, they concluded that there was no price premium caused by the energy label itself. Indeed, they suggested that the positive price premium of the EPCs found in the former studies was the result of the methodological design rather than evidence of the impact of EPCs.

Olaussen et al. took advantage of the fact that the EPC system was implemented in Norway by the government "overnight" on July 1 2010. This meant they had a quasi-natural experimental design with pre- and post- EPC data [11]. For each dwelling that was sold before the implementation of the EPCs in 2010, they identified the energy label that the same dwelling was given when resold in 2014. Interestingly, when using the energy labels of dwellings resold in 2014 as a variable in a hedonic regression for dwellings sold before the introduction of the EPC system, they found the same positive relationship between energy labels and the transaction prices. This means that the positive price effect of the energy label was present even before it was implemented, which strongly suggests that the studies that found positive price effects from the energy label captured something other than the effects of the label itself.

However, Olaussen et al. and many other earlier studies on the impact of EPCs on transaction prices did not account for changes in the energy prices in their analyses [11]. Indeed, looking at the development of the energy price in Oslo, a trend is observed whereby the energy price increases, reaching a peak in 2010, and then decreases. As 2010 was the year in which the EPC was implemented in Norway, it is possible that the lower energy price in the post-label period actually neutralizes the potential price premium of the EPC implementation. To gain a more comprehensive understanding of the impact of EPCs on transaction prices, we include a time series for the energy price in the analysis.

Based on the energy price time series, as well as extracting information about the expected energy consumption of buildings from their assigned energy label, we calculate the expected annual energy cost of buildings. Moreover, following Olaussen et al., we utilize the fact that energy labels were implemented overnight on 1 July 2010 [11]. Instead of focusing on labels, we now focus directly on the energy consumption. Therefore, to each dwelling sold before the implementation of the EPCs, we assign the same expected annual energy use that was calculated for that dwelling when it was resold after 2010. Thus, using a hedonic regression, we can assess whether the post-label impact of the expected annual energy cost on transaction prices is stronger than the pre-label impact. Our results 
indicate that the impact of the expected energy costs on transaction prices is more moderate after the implementation of the EPCs.

The paper is organized as follows. Section 2 outlines the energy labeling system and some descriptive statistics. Section 3 describes the method, and the results of the empirical analysis are presented in Section 4. A discussion and concluding remarks are provided in Section 5.

\section{The Energy Labeling System for Dwellings and Houses}

The energy performance of buildings directive (EPBD) is the EU's main legislative instrument to improve the energy performance of buildings [12]. Based on the EPBD, the EPC system was implemented gradually throughout different member states from 2006. The final deadline for implementing an EPC system in the member states was 2009. A recasting of the EPBD [13] in 2010 strengthened the role of EPCs by demanding that when buildings "are offered for sale or for rent, the energy performance indicator of the energy performance certificate of the building or the building unit, as applicable, is stated in the advertisements in commercial media" [13] (p. 24), rather than at the time of signing a purchase agreement or rental contract [1].

In most EU member states, the energy performance ratings are expressed on a letter scale, for instance, from A to G, where A is very efficient and G very inefficient, and this is also the case in Norway. As improved energy performance of buildings are supposed to increase sales prices and rents, the EPC is intended to generate incentives among owners to invest in improving energy efficiency [1]. Still, the implementation of EPCs has been slow in EU, and it has been argued that both the implementation and quality of certification schemes vary from country to country [1].

As mentioned in the introduction, the EPC system was fully implemented in Norway on 1 July 2010. The Ministry of Petroleum and Energy and the Ministry of Local Government and Regional Development were given overall responsibility for the introduction, with the Norwegian Water Resources and Energy Directorate (NVE) as the authority in charge of the certification and inspection schemes [14]. The EPC system was fully mandatory from the beginning, that is, from July 2010, and since then all transactions involving houses and dwellings in Norway must be accompanied by an EPC.

The EPC is a legal document that is required to be shown to the buyer. However, parts of the certificate, for example the Energy Label, can be used as a simplifying short version [14]. Among other details, the document contains data identifying the building, the agent issuing the certificate, the energy label (which represents the calculated delivered energy need) on a scale from A to G, the heating grade (which represents to what extent heating of space and water can be done with renewable energy sources) represented by color grades, advice on how to save energy, and some general recommendations to the buyer [14]. (Since most Norwegian homes use electric heating, the Norwegian EPC system focuses on energy consumption.)

The operational liability of the EPC system in Norway is with ENOVA. (ENOVA is a state-owned company owned by the Ministry of petroleum and energy until July 2018 and then by the Ministry of climate and environment. ENOVA is responsible for funding cost efficient changes in energy production and consumption.) For the owners of existing buildings, there is a self-assessment option in the certification scheme. Normally, these certificates are less detailed than those carried out by professionals, and the cost of the certification process for these buildings is typically at least NOK 1000 (NOK = Norwegian kroner). The hedonic regressions in the studies from the different countries we have referred to in the introduction show surprisingly similar values regardless of whether the EPC scheme was based on self-assessments or assessments made by experts. This includes both the assessment of the quality of the dwelling with respect to energy efficiency and the extra advertising costs associated with selling when energy label information is included. When it comes to new buildings, a qualified expert is required for certification and, hence, it is more expensive than for existing buildings. The quality assurance aspect of the Norwegian certification system is attended to by controls in the market, where wrong inputs may be considered a breach of contract. In such cases, a fine may be issued. The 
transaction process is supervised by the Norwegian Water Resources and Energy Directorate (NVE), which supervises whether EPCs are presented at sale, whether the EPCs reflect the actual energy efficiency standard of the building, and whether the experts meet the competence requirements [14].

\section{Methods}

We utilize two methods to analyze the effect of EPCs on the value of dwellings when taking the present value of the energy price into account. Both methods build on Gordon's dividend model in hedonic regression [15]. In the first method, the dividend model is utilized to calculate the expected value added of each energy label. This expected value added is compared with the estimate for the actual value added, which is estimated based on the hedonic regression. The second method is a hedonic regression model in which the energy price and the rate of discount are included by using the present value of the expected energy cost as an explanatory variable.

\subsection{Calculating Expected Value Added}

Gordon and Shapiro's growth model is written as follows [15]:

$$
P V_{0}=\frac{D_{1}}{r-g}
$$

where $P V_{0}$ is the items value at time $t=0, D_{1}$ is the expected dividend at time $t=1$, and $r$ is the demand on return. When we use this model with respect to the dwelling and energy consumption, we can define $P V_{0}$ as the future energy cost and $D_{t}$ as the yearly energy cost of the dwelling. If the yearly energy cost is expected to grow with a yearly rate of $g$, we can rewrite the model as follows (The formula calculates the maximum present value (PV) of energy cost, and may overestimate the theoretical costs for dwellings that have a small remainder life expectancy. We expect most of these dwellings to fall in the G category.):

$$
P V_{0}=\frac{D_{1}}{r-g}=\frac{D_{0}(1+g)}{r-g}
$$

To find the yearly energy cost $D_{0}$, we calculate the maximum energy consumption per square meter in the different energy label categories. This energy consumption is calculated based on the demands from the Norwegian Water Resources and Energy Directorate. The formula for the different labels is presented in Table 1. The only requirement for the G category is that the energy consumption is higher than in the F category. We calculate this category by assuming that energy consumption is $25 \%$ higher than in the F category, which is based on the average difference in energy consumption between the $\mathrm{F}$ and $\mathrm{G}$ categories. Table 1 shows the maximum energy consumption associated with each energy label category.

Table 1. Formula for calculating the maximum energy consumption associated with each energy label category [16].

\begin{tabular}{cccccccc}
\hline \multicolumn{7}{c}{ Delivered Energy per $\mathbf{m}^{2}$ Heated $^{\left(\mathbf{k W h} / \mathbf{m}^{2}\right)}$} \\
\hline $\begin{array}{c}\text { Type of } \\
\text { Dwelling }\end{array}$ & $\mathbf{A}$ & $\mathbf{B}$ & $\mathbf{C}$ & $\mathbf{D}$ & $\mathrm{E}$ & $\mathrm{F}$ & $\mathrm{G}$ \\
\cline { 2 - 9 } & $\leq$ & $\leq$ & $\leq$ & $\leq$ & $\leq$ & $\leq$ & No Limit \\
\hline Apartment & 85 & 95 & 110 & 135 & 160 & 200 & $>\mathrm{F}$ \\
\hline $\begin{array}{c}\text { Other } \\
\text { dwellings }\end{array}$ & 95 & 120 & 145 & 175 & 205 & 250 & $>\mathrm{F}$ \\
& $+600 / \mathrm{A}$ & $+1000 / \mathrm{A}$ & $+1500 / \mathrm{A}$ & $+2200 / \mathrm{A}$ & $+3000 / \mathrm{A}$ & $+4000 / \mathrm{A}$ & \\
\hline
\end{tabular}


For instance, a 100-square meter apartment must not exceed the maximum limit of $105 \mathrm{kWh} / \mathrm{m}^{2}$ $(95+10,000 / 100)$ for energy consumption to earn a grade B on its EPC. A dwelling without a heat pump and solar energy that was built in accordance with the minimum requirements of the building regulations will normally achieve a grade C. Grade B may be earned, for example, by installing a heat pump to utilize solar energy or by improving the insulation of windows. Grade A is only achieved by dwellings wherein all measures of energy efficiency are adopted. Few dwellings achieve grades A or B. Tables 2 and 3 show the distribution of energy grades for small houses and apartments, respectively. Table 4 presents the distribution after 2010 and the calculated distribution before 2010 based on our data.

Table 2. The distribution (number of new certificates) of energy labels for small houses [17].

\begin{tabular}{cccccccc}
\hline Year & A & B & C & D & E & F & G \\
\hline $\mathbf{2 0 1 4}$ & 310 & 3274 & 6635 & 7689 & 7709 & 10,802 & 17,417 \\
$\mathbf{2 0 1 3}$ & 318 & 2079 & 5415 & 10,587 & 10,148 & 14,535 & 13,228 \\
$\mathbf{2 0 1 2}$ & 221 & 1323 & 5017 & 13,129 & 11,660 & 16,546 & 9504 \\
$\mathbf{2 0 1 1}$ & 45 & 819 & 4030 & 13,515 & 11,991 & 14,063 & 6310 \\
$\mathbf{2 0 1 0}$ & 20 & 340 & 3000 & 9701 & 8665 & 7394 & 2239 \\
\hline
\end{tabular}

Table 3. The distribution (number of new certificates) of energy labels for apartments [17].

\begin{tabular}{cccccccc}
\hline Year & A & B & C & D & E & F & G \\
\hline $\mathbf{2 0 1 4}$ & 889 & 3495 & 4867 & 7954 & 7375 & 9171 & 11,180 \\
$\mathbf{2 0 1 3}$ & 339 & 2524 & 4813 & 9466 & 7100 & 10,555 & 11,352 \\
$\mathbf{2 0 1 2}$ & 122 & 1624 & 4424 & 11,356 & 6529 & 11,849 & 11,222 \\
$\mathbf{2 0 1 1}$ & 97 & 999 & 3377 & 8412 & 5887 & 9596 & 6724 \\
$\mathbf{2 0 1 0}$ & 0 & 169 & 1501 & 5144 & 4118 & 4848 & 2982 \\
\hline
\end{tabular}

Table 4. EPCs and sale year.

\begin{tabular}{ccccccccc}
\hline Year & A & B & C & D & E & F & G & Total \\
\hline $\mathbf{2 0 1 4}$ & 2 & 40 & 209 & 367 & 306 & 474 & 633 & 2031 \\
$\mathbf{2 0 1 3}$ & 1 & 11 & 44 & 58 & 45 & 52 & 98 & 309 \\
$\mathbf{2 0 1 2}$ & 0 & 12 & 37 & 42 & 28 & 44 & 55 & 218 \\
$\mathbf{2 0 1 1}$ & 0 & 7 & 33 & 48 & 14 & 60 & 69 & 231 \\
$\mathbf{2 0 1 0}$ (July-Dec) & 0 & 0 & 3 & 14 & 6 & 15 & 29 & 67 \\
\hline $\mathbf{2 0 1 0}$ (Jan-June) & 0 & 0 & 6 & 24 & 10 & 22 & 27 & 89 \\
$\mathbf{2 0 0 9}$ & 0 & 0 & 25 & 48 & 33 & 44 & 52 & 202 \\
$\mathbf{2 0 0 8}$ & 0 & 2 & 20 & 55 & 30 & 40 & 61 & 208 \\
$\mathbf{2 0 0 7}$ & 0 & 0 & 16 & 58 & 28 & 41 & 65 & 208 \\
$\mathbf{2 0 0 6}$ & 0 & 1 & 29 & 53 & 31 & 59 & 68 & 241 \\
$\mathbf{2 0 0 5}$ & 0 & 2 & 15 & 42 & 30 & 55 & 64 & 208 \\
$\mathbf{2 0 0 4}$ & 0 & 0 & 9 & 41 & 23 & 52 & 52 & 177 \\
$\mathbf{2 0 0 3}$ & 0 & 0 & 6 & 30 & 34 & 45 & 66 & 181 \\
$\mathbf{2 0 0 2}$ & 0 & 0 & 2 & 29 & 31 & 58 & 63 & 183 \\
$\mathbf{2 0 0 1}$ & 0 & 0 & 1 & 8 & 15 & 35 & 29 & 88 \\
$\mathbf{2 0 0 0}$ & 0 & 0 & 1 & 8 & 12 & 19 & 15 & 55 \\
\hline Total & 3 & 75 & 456 & 925 & 676 & 1115 & 1446 & 4693 \\
\hline
\end{tabular}

Note: The table shows the number of dwellings sold in a given year with a given EPC grade after July 2010 and the implicit EPC grade before July 2010.

Then, the energy consumption per square meter $\left(\mathrm{kWh} / \mathrm{m}^{2}\right)$ is used to calculate the yearly energy cost for each dwelling as follows:

$$
\text { Yearly energy cost }=\frac{k w h}{m^{2}} \cdot m^{2} \cdot p_{t}^{e}
$$


where $P_{t}^{e}$ is the energy cost at time $\mathrm{t}$ measured in NOK/kwh. By applying the present value for the grade A dwellings and subtracting the present value of a dwelling in the grade $\mathrm{B}$ category, we find the expected value added of a grade A labeled dwelling. This value added can be compared with the value added found in the market transaction data to test whether the expected energy label premium is achieved in the market.

\subsection{Estimating the Actual Energy Label Premium}

The real energy label price premium is estimated based on a hedonic regression model and real estate transaction data. The hedonic model is used to control for heterogeneity with respect to different characteristics, with dummy variables for the different energy labels included as follows:

$$
\ln P_{n}^{t}=\beta_{o}^{t}+\sum_{k=1}^{K} \beta_{k} z_{n k}^{t}+\varepsilon_{n}^{t}
$$

Here, the logarithm of the dwelling price per square meter, $\mathrm{P}$, is explained by a set of explanatory variables $z_{n k}^{t}$. The explanatory variables $z$ comprise age, location, dwelling type, energy label, and dwelling size, and $\varepsilon_{n}^{t}$ is the error term.

First, the explanatory variables are the energy labels from $A$ to $G$, with $F$ as the reference (baseline) energy label. $F$ is chosen instead of $G$ as the baseline because of the unique characteristics of the $G$ category. We found that the $\mathrm{G}$ category includes all dwellings where sellers neglect to identify the energy label. For example, if the owner of a $\mathrm{C}$ label dwelling neglects to go through the labeling process, the dwelling will automatically get a $G$ label. Second, the age variable measures the difference between the year of the sale and the construction year of the dwelling. As this difference probably is of less importance the older the dwelling is, we measure the age variable by $1 /$ (sale year - construction year). This accounts for the fact that the age of a building is a relatively more important factor if we compare a brand-new dwelling with a one-year-old dwelling than if we compare a 20-year-old with a 21-year-old dwelling. Because of the way the variable is constructed, we expect it to be positively corelated with the house price. Third, we include dummy variables for location based on the different city districts in Oslo (St. Hanshaugen, Gamle Oslo, Grynerløkka og Sagene, Outer Oslo West, Outer Oslo East), where the district Frogner is used as the baseline (it would have been preferable to include smaller, and hence more urban, districts, but the number was chosen based on the number of observations. See Marmolejo-Duarte and Chen (2019) [18]). Fourth, we control for dwelling type, where we separate single-family houses, townhouses, and semidetached houses with dummies, and where apartment is the baseline category. Fifth, we also include dummy variables for different size of the dwellings. Small is a dummy for dwellings between $50-80 \mathrm{~m}^{2}$, medium is dummy for dwellings from $81-120 \mathrm{~m}^{2}$, and large is dummy for dwellings $>120 \mathrm{~m}^{2}$. Hence, the baseline size is $<50 \mathrm{~m}^{2}$. We use the log-linear (semilog) functional form in the regressions because it makes it easier to interpret the coefficients and because the semilog functional form is known to mitigate the problem of heteroscedasticity [19]. In total, we observe $(T+1)$ periods. Note that if we ignore the year dummies and the time subscript, we are left with a standard hedonic model. Based on Equation (4), we are hence able to estimate two models, the post-label hedonic model, Model 1, and the pre-label hedonic model, Model 2.

Based on the results from the model, we estimate the price per square meter for the reference dwelling, which is a dwelling $<50 \mathrm{~m}^{2}$ located in Frogner. We set the age of this dwelling at five years and calculate the square meter price for all energy label categories. The price difference between the different labels is the actual value added achieved in the market compared with the expected value added.

\subsection{Hedonic Model With Energy Price and Rate of Discount}

To examine how the energy label, energy price, and rate of discount affect the price of the dwelling, a hedonic model is constructed where these three factors are represented through the expected energy 
cost. Hence, we apply the same model as described above, but replace the energy label dummies with the expected value of the energy costs given by:

$$
L N(P V \text { energy cost })=L N\left(\frac{k W h \cdot P_{t}^{e}}{r_{t}-g_{t}}\right)
$$

Here, the logarithm of the present value per square meter, $\mathrm{PV}$, is given by taking the logarithm of energy consumption per square meter times the expected energy cost per square meter, divided by the discount rate minus the growth rate. Figure 1 illustrates the development in energy price and discount rate over the time period 2000-2014.

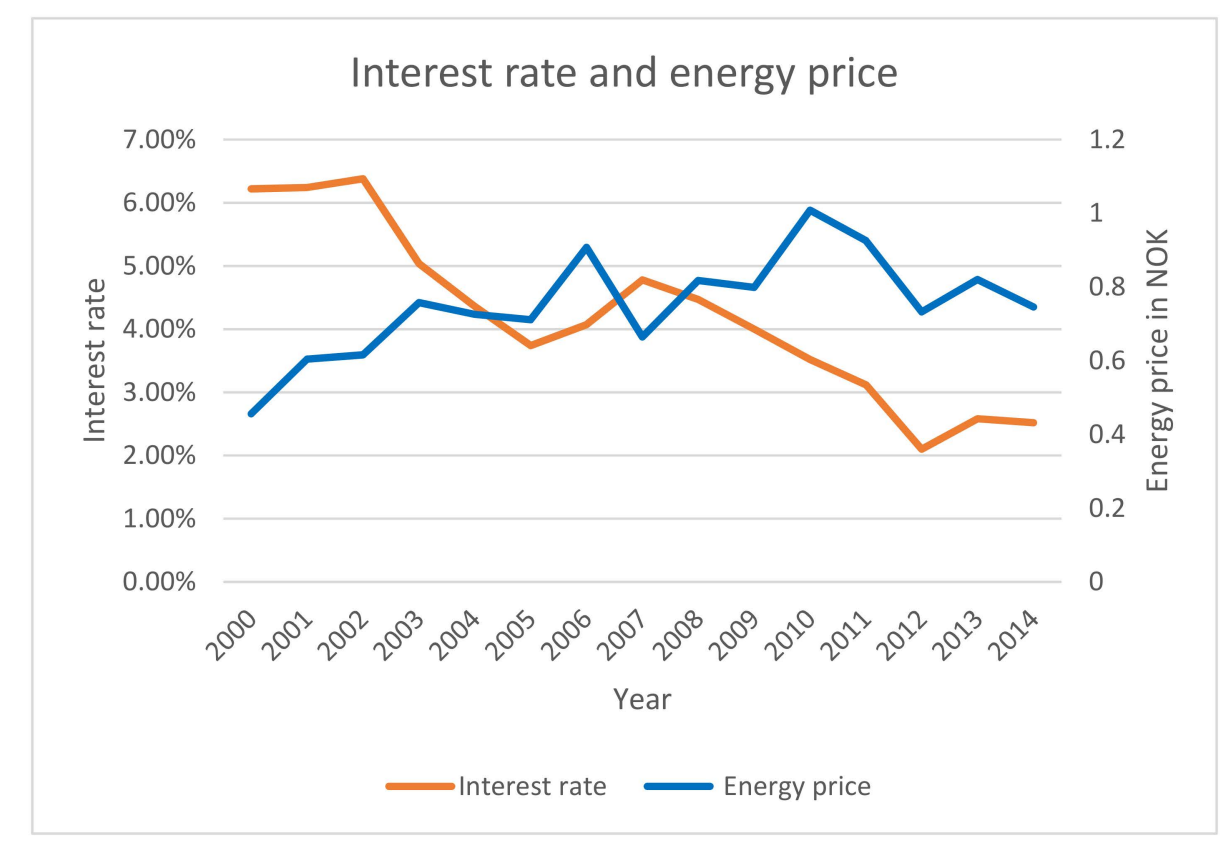

Figure 1. Energy price and interest rate year 2000-2014. The interest rate is given by the Norwegian 10-year government bond and the energy price is from the energy price area of Oslo [20-22].

\section{Results}

The yearly energy costs are used to calculate the present value of the different energy labels. In Figure 2, this is illustrated with an example from a $40 \mathrm{~m}^{2}$ apartment. Note that there is a distinct difference between present values in 2009 and 2014. This difference is due to the discount rate being lower in 2014 than in 2009. This effect dominates, even if the energy price is slightly higher in 2009 than in 2014 (see Figure 1).

The expected price premiums of the energy labels in 2014 are presented in Table 5 and those for 2009 in Table 6. The price premiums are given per square meter. For instance, if we take an apartment of $40 \mathrm{~m}^{2}$ with the energy label C, the expected price premium is NOK 682 per square meter, compared with a similar apartment with the energy label D. The same comparison in 2009 (Table 6) yields a price difference of NOK 502. 


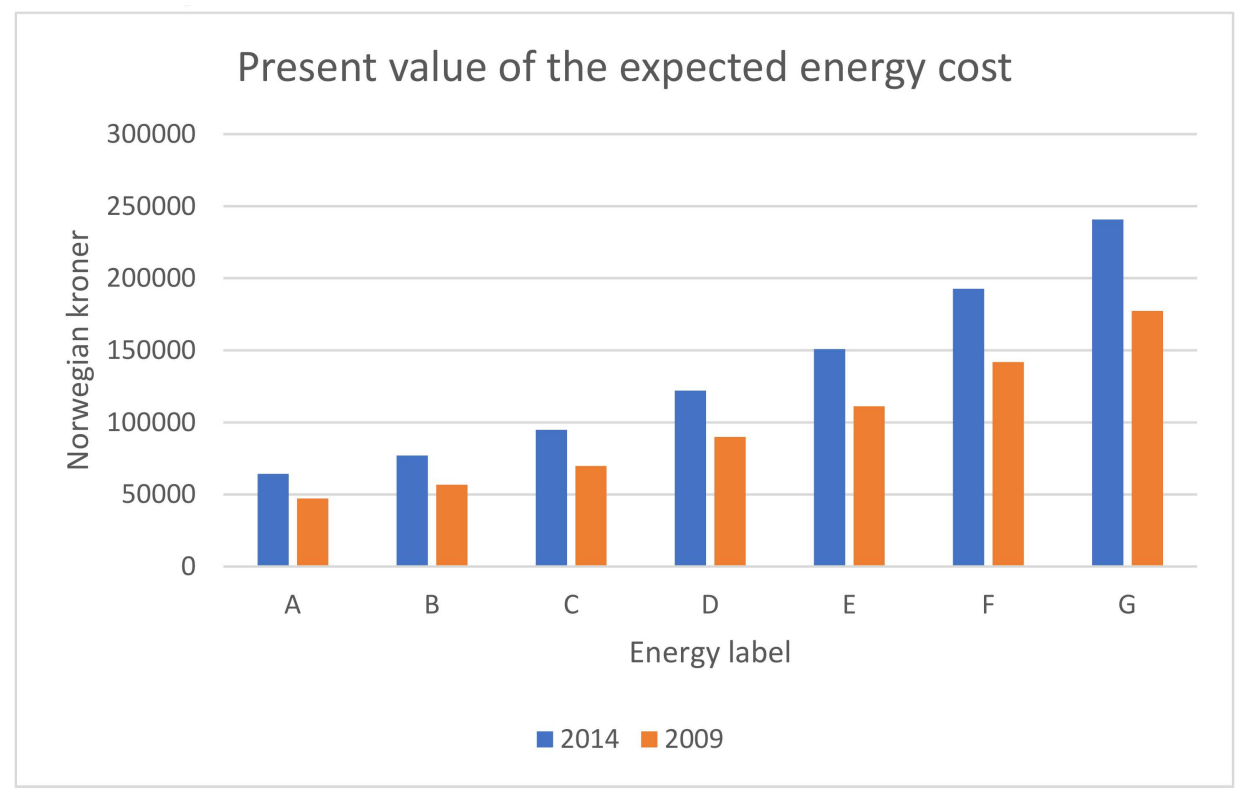

Figure 2. Present value of the expected energy cost for different EPCs. The figure shows the present value of the expected energy cost for a $40 \mathrm{~m}^{2}$ apartment in 2009 and 2014 for different EPC grades in Norwegian kroner (NOK). (NOK $1=€ 0.11$ (per 31.12.2014)).

Table 5. Expected price premium per $\mathrm{m}^{2}$ from different EPCs in 2014 in NOK.

\begin{tabular}{ccccccccc}
\hline B & 321 & & & & & & \\
C & 763 & 442 & & & & & \\
D & 1445 & 1124 & 682 & & & & \\
E & 2168 & 1846 & 1405 & 723 & & & \\
F & 3211 & 2890 & 2449 & 1766 & 1044 & 1204 & \\
G & 4416 & 4094 & 3653 & 2970 & 2248 & F & G \\
\hline & A & B & C & D & E & F \\
\hline
\end{tabular}

Table 6. Expected price premium per $\mathrm{m}^{2}$ from different EPCs in 2009 in NOK.

\begin{tabular}{ccccccccc}
\hline B & 236 & & & & & & \\
C & 561 & 325 & & & & & \\
D & 1064 & 827 & 502 & & & & \\
E & 1596 & 1359 & 1034 & 532 & & & \\
F & 2364 & 2128 & 1802 & 1300 & 768 & 886 & \\
G & 3250 & 3014 & 2689 & 2187 & 1655 & F & G \\
\hline
\end{tabular}

The difference between the expected and actual value added is interesting. First, for 2014, we find that the actual value added (Table 7) is higher than the expected price premium (Table 5). This implies that dwellings with better energy labels receive a higher premium than can be explained by the energy costs; that is, a value added beyond the cost savings expected from a more energy-efficient dwelling. The pattern is confirmed in the 2009 tables (Tables 7 and 8). This means that, even before the energy labels were available to buyers, there was a price premium beyond what could be explained by the energy cost. However, these results are dependent on the rate of discount and sensitivity analysis shows that if the rate of discount in 2014 was set at 4\%, the difference between the actual and expected price premium is much lower. 
Table 7. Estimated (actual) price premium per $\mathrm{m}^{2}$ from different EPCs in 2014 in NOK.

\begin{tabular}{cccccccc}
\hline B & & & & & & & \\
C & 2715 & & & & & \\
D & 5667 & $2952(4 \%)$ & & & & \\
E & 11,486 & $8771(12 \%)$ & $5819(8 \%)$ & & & \\
F & 12,229 & $9514(13 \%)$ & $6562(9 \%)$ & 743 & & \\
G & & 8203 & 5488 & 2536 & -3283 & -4026 & \\
\hline & A & B & C & D & E & F & G \\
\hline
\end{tabular}

Table 8. Estimated (actual) price premium per $\mathrm{m}^{2}$ from different EPCs in 2009 in NOK.

\begin{tabular}{cccccccc}
\hline B & & & & & & & \\
C & 8456 & & & & & \\
D & 9182 & $726(1 \%)$ & & & & \\
E & & 12,714 & $4258(9 \%)$ & $3531(7 \%)$ & & & \\
F & & 14,132 & $5676(12 \%)$ & $4950(11 \%)$ & 1418 & & \\
G & & 13,048 & 4593 & 3866 & 335 & -1084 & \\
\hline & A & B & C & D & E & F & G \\
\hline
\end{tabular}

Table 9 presents the results from the hedonic models for the period after the introduction of EPCs (post-label), Model 1, and before the introduction of labels (pre-label), Model 2. All coefficients have the expected sign and are significant at the $1 \%$ level, except for the two location dummies for the districts of St. Hanshaugen and Outer Oslo West in Model 2, which are significant at the 5\% level. The most interesting result in this analysis is the present value of the energy cost per square meter, which is positive and significant at the $1 \%$ level in both 2014 and 2009. The difference between the coefficients is rather small and not significantly different at the $1 \%$ level. Note that the $1 \%$ confidence intervals for the 2014 coefficient $(0.061-0.119)$ and the 2009 coefficient (0.029-0.133) overlap significantly. Note also that the overall results do not change if we substitute the present value of the energy cost per square meter with the expected energy cost per square meter, or if we look at different dwelling types separately (these results are not reported in the paper).

Table 9. Energy costs and dwelling prices. Hedonic models, dependent variable: natural logarithm of transaction prices per $\mathrm{m}^{2}$.

\begin{tabular}{ccc}
\hline & $\begin{array}{c}\text { Post-Label } \\
\text { Model 1: 2014 } \\
\text { Coef. (Std. Err.) }\end{array}$ & $\begin{array}{c}\text { Pre-Label } \\
\text { Model 2: Before July 2010 } \\
\text { Coef. (Std. Err.) }\end{array}$ \\
\hline Ln PV energy cost & $-0.090^{* * *}(0.011)$ & $-0.081^{* * *}(0.020)$ \\
Age & $0.132^{* * *}(0.021)$ & $0.080^{* * *}(0.020)$ \\
St. Hanshaugen & $-0.115^{* * *}(0.026)$ & $-0.072^{* *}(0.034)$ \\
Gamle Oslo & $-0.283^{* * *}(0.027)$ & $-0.207^{* * *}(0.033)$ \\
Grynerløkka og Sagene & $-0.249^{* * *}(0.024)$ & $-0.140^{* * *}(0.028)$ \\
Outer Oslo West & $-0.198^{* * *}(0.023)$ & $-0.078^{* *}(0.027)$ \\
Outer Oslo East & $-0.502^{* * *}(0.023)$ & $-0.368^{* * *}(0.027)$ \\
Single-family houses & $0.105^{* * *}(0.019)$ & $0.090^{* * *}(0.027)$ \\
Townhouses & $0.050^{* * *}(0.017)$ & $0.090^{* * *}(0.022)$ \\
Semidetached houses & $0.087^{* * *}(0.018)$ & $0.070^{* * *}(0.025)$ \\
Small & $-0.125^{* * *}(0.011)$ & $-0.078^{* * *}(0.014)$ \\
Medium & $-0.120^{* * *}(0.015)$ & $-0.107^{* * *}(0.019)$ \\
Large & $-0.220^{* * *}(0.021)$ & $-0.183^{* * *}(0.027)$ \\
Constant & $12.352^{* * *}(0.143)$ & $12.097^{* * *}(0.026)$ \\
Adj R-squared & $0.47^{*}$ & 0.40 \\
Number of observations & 2789 & 1608 \\
\hline
\end{tabular}

Note: ${ }^{* * *},{ }^{* *}$, signal significance at the $1 \%$ and $5 \%$ levels, respectively. See Section 3.2 above for variable definitions. 
House prices are in fixed 2014 prices, and every dwelling price is multiplied by the house price index value for 2014 divided by the house price index value of the year of the transaction. Model 1 hence consists of buildings sold in 2011-2014, in 2014 prices.

\subsection{Robustness Check}

The nature of the potential causal relationship between energy labels and sales prices is crucial for our analysis. As a robustness check to test this relationship, we utilize the natural experiment that took place when the energy labels became mandatory in July 2010. The data allow us to compare the transaction prices of dwellings sold before and after the introduction of the EPC system in July 2010. If energy labels affect the sale prices, then two houses sold in, for example, 2008, for approximately the same price, should have approximately the same price as each other when resold after July 2010 if they were given the same energy label. On the other hand, if one of them received a higher energy label than the other, it should, ceteris paribus, have a higher resale price.

\subsubsection{The Weighted Repeat Sales Method}

The robustness check is performed with the weighted repeat sales method. The following model is applied [23,24]:

$$
\ln \left(p_{n}^{t} / p_{n}^{s}\right)=\sum_{t=0}^{T} \gamma_{t} D_{n}^{t}+\mu_{n}^{t}
$$

where $P_{n}^{t}$ is the price at the time of the resale, $p_{n}^{s}$ is the price of the previous sale, $D_{n}^{t}$ is a dummy variable with the value 1 in the period in which the resale occurs, -1 in the period in which the previous sale occurs, and 0 otherwise. $\mu_{n}^{t}$ is the error term. To account for the possibility that the residual variance increases with increasing time intervals between sales, we apply the weighted repeat sales (WRS) method developed in [23].

The data does not contain enough observations before the introduction of the energy performance certificates in 2010 to create indices for energy label A and energy label B. To remove the house price trend, we divide the indices with a repeated sales index constructed based on all the dwellings in the dataset. We use a simple Dickey-Fuller test, to test whether variables are stationary (Table 10). All the variables have one unit root and are thus differentiated to make them stationary.

Table 10. Dickey-Fuller tests for unit root of all variables.

\begin{tabular}{ccccc}
\hline \multirow{2}{*}{ Variables } & \multicolumn{2}{c}{ Levels } & \multicolumn{2}{c}{ First Differences } \\
\cline { 2 - 5 } & Test Statistic & Critical Value & Test Statistic & Critical Value \\
\hline PV energy cost & -2.269 & -3.000 & -3.042 & -3.000 \\
C & -5.207 & -3.000 & -6.935 & -3.000 \\
D & -4.922 & -3.000 & -8.628 & -3.000 \\
E & -2.302 & -3.000 & -5.713 & -3.000 \\
F & -3.642 & -3.000 & -5.763 & -3.000 \\
G & -2.194 & -3.000 & -4.313 & -3.000 \\
\hline
\end{tabular}

Note: The 5\% interpolated Dickey-Fuller critical values are used. No lags are included in the test. Ln means that natural logarithms have been used. $\mathrm{C}=$ index with dwellings with energy label $\mathrm{C}$; $\mathrm{D}=$ index with dwellings with energy label D; E = index with dwellings with energy label E; F = index with dwellings with energy label F; and $\mathrm{G}=$ index with dwellings with energy label $\mathrm{G}$.

We use a Durbin Watson test and a Portmanteau test for white noise which shows indication of autocorrelation AR (1). To reduce the problem of autocorrelation, we apply a Prais-Winsten regression [25].

Our regression is:

$$
Y^{\prime}=\beta_{0}(1-\rho)+\sum \beta_{j} x^{\prime}{ }_{j t}+\sum \delta_{j} s_{j t}+\varepsilon_{j t}
$$


where $\beta_{j}$ is the coefficient for the $j$ th explanatory variable $x, \delta_{j}$ is the coefficient for the $j$ th dummy variable $s$, and $\varepsilon_{j t}$ is the error term. The symbol ' indicates the transformation of the variables. The explanatory variable is the present value of the energy cost in the different categories. In addition, we use a dummy for the time when the energy labeling was made mandatory, from July to December 2010.

\subsubsection{Repeat Sales Results}

We start to explore the effect of introducing energy labels by constructing price indices for the different labels and let them all have a value of 100 in the year 2000 (Figure 3). The figure shows some price variations, but do not indicate a price effect from the energy performance certificates in July 2010. If energy labeling has the price effect found in the hedonic data, we should expect a kink with an increasing slope after July 2010 for the most energy efficient energy labels. However, it is difficult to ascertain any shift taking place in July 2010.

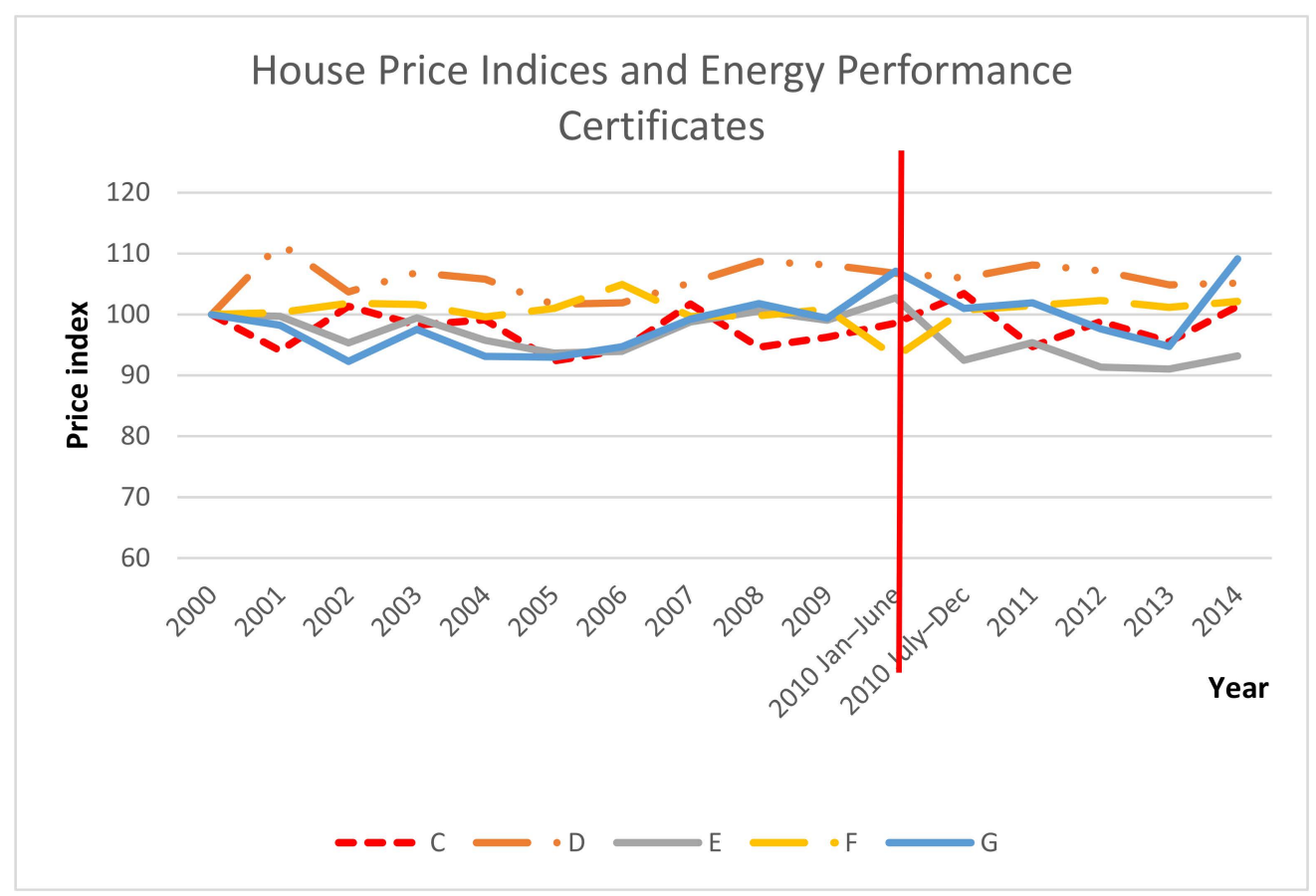

Figure 3. Dwelling price indices in different energy label categories. All of the indices start at 100 in year 2000 (Note: Fixed house price indices between 2000 and 2014, with trend removed. All indices start at 100 in 2000. As energy labeling was made mandatory on 1 July 2010, the year 2010 has been given two data points in the indices, one for January-June and one for July-December. The vertical line indicates when the energy labeling became mandatory. $\mathrm{C}=$ index for dwellings with energy label $\mathrm{C}$; $\mathrm{D}=$ index for dwellings with energy label $\mathrm{D} ; \mathrm{E}=$ index for dwellings with energy label $\mathrm{E} ; \mathrm{F}=$ index for dwellings with energy label F; and $G$ = index for dwellings with energy label G).

In Table 11 we test for the effect of introducing energy labels controlling for the present value of the energy cost. The dependent variable is the house price in the different energy label categories, and where we regress on the main index as well a dummy variable for the second part of 2010, when the energy label was made mandatory. The adjusted R-squares are all negative, while the Durbin Watson statistics, transformed after using the Prais-Winsten regression, range from 1.59 to 2.40, which means that we keep the null hypothesis of zero autocorrelation. (With $n=15$ and $k=2$, the retained $\mathrm{H} 0$ critical values range from 1.25 to 2.75 .) If energy labeling has the price effect found in the post-label hedonic data, we should expect significant dummy coefficients in Table 11. However, none of the dummies are significant, nor the present value of energy cost. Hence, despite the strong label effect demonstrated in the hedonic post-label model (Model 1), just as in the pre-label hedonic regression (Model 2), we find 
no evidence to support the price premium effect. We also find no price effect from the present value of energy cost.

Table 11. House price under different energy labels.

\begin{tabular}{cccccc}
\hline & Ln C & Ln D & Ln E & Ln F & Ln G \\
\hline Dummy 2010 & -0.001 & -0.004 & -0.015 & 0.012 & -0.001 \\
July-Dec & 0.000 & 0.000 & 0.000 & 0.000 & 0.000 \\
PV energy cost & -0.154 & -0.079 & -0.051 & -0.042 & -0.138 \\
Adj. R & & 1.587 & 1.797 & 2.399 & 1.754 \\
DW transf. & 2.134 & &
\end{tabular}

Note: We compare how well the dummy for the period when energy labeling was made mandatory (July-December 2010) together with the PV of energy cost is able to explain the house prices indexes for different energy labels. Ln $C=$ logarithmic house price index with dwellings with energy label $C ;$ Ln $D=$ logarithmic house price index with dwellings with energy label $\mathrm{D}$; $\mathrm{Ln} \mathrm{E}=$ logarithmic house price index with dwellings with energy label $\mathrm{E}$; Ln F = logarithmic house price index with dwellings with energy label F; and $\operatorname{Ln} G=$ logarithmic house price index with dwellings with energy label G. DW transf. refers to the Durbin-Watson statistic, transformed after using the Prais-Winsten regression.

\section{Discussion and Concluding Remarks}

The energy performance certificate system was introduced in Europe to provide buyers with better information about the energy performance of dwellings. In part, the aim of this policy was to provide better valuations of dwellings when they are sold and to give buyers incentives to purchase energy-efficient dwellings. Earlier studies in this area have yielded contradictory conclusions. Brounen and Kok found that there was a significant price premium associated with energy labels in the real estate market in the Netherlands [4], whereas other studies, such as Murphy, found little or no effect of energy labels in the same market [6]. The present paper follows up the study by Olaussen et al. of the Norwegian real estate market [11]. Replicating the hedonic model by Brounen and Kok for Norwegian data, Olaussen et al. found the same results as Brounen and Kok $[4,11]$. However, when running a fixed effect model with data before and after the introduction of energy labels in 2010, they found that something other than the energy label must explain the apparent price premium. One potential explanation for this is that the energy efficiency of the dwelling was known to the buyers even before the labeling system was issued. To test for this, we use the energy price over time to see if the cost of energy may be the underlying explanation. By controlling for the present value of the expected energy consumption, we find no evidence of energy costs being important for the energy label premium.

By applying data for energy prices and the rate of discount, and the associated demands for the different energy label categories, we calculate the expected price premium that dwellings with better energy labels should achieve compared with similar dwellings with lower energy labels. Then, these price premiums are compared with the actual price premiums estimated in the hedonic models. The analyses show that the actual price premiums are much higher than the expected price premiums based on the energy cost differences. Moreover, we find this difference both before and after the energy label system was introduced. In addition, we find no significant differences in the actual price premium before and after the introduction of the energy labels in 2010. The same results are provided by the robustness check, in which we apply the repeated sales method; that is, we find that the present value of energy costs has no effect on the price of dwellings.

These results support previous studies that showed that the energy label does not affect the price of dwellings at the time of sale $[11,26,27]$. This is in line with the inferences of several survey studies, which indicate that when people buy a dwelling, they pay considerably less attention to its energy performance compared with other factors, such as the availability of garden and outdoor space, the location, the neighborhood, and the size of the property. Hence, there are reasons to believe that, when energy labels have been associated with price premiums in other studies, this results from factors other than the energy labels themselves. One explanation for our result may be that the buyers are well informed about the energy efficiency of the dwellings even without the energy labels and, hence, were 
already well informed before the energy label system was introduced. Another explanation may be that we have omitted explanatory variables in our models. Potential omitted variables may be the standard of the dwelling, for example, how recently it was renovated, or different amenities associated with the building. This explanation is in line with [26-28]. These omitted variables were visible to buyers before the energy label system was introduced, and it is quite likely that, e.g., the dwelling standard is closely correlated with the energy efficiency. Hence, it may be that the price premium associated with the energy label is explained by the standard of the dwelling. However, data regarding when dwellings have been renovated are not easily accessible. A detailed, in-depth study of potential omitted variables correlated with EPCs may be a fruitful path for future research.

Author Contributions: All authors have contributed equally, L.K. prepared an initial first draft, which was completed, corrected, reviewed and revised by J.O.O., A.O., and J.T.S.

Funding: This research received no external funding.

Conflicts of Interest: The authors declare no conflict of interests.

\section{References}

1. Bio Intelligence Service; Lyons, R.; Institute for European Environmental Policy. Energy Performance Certificates in Buildings and Their Impact on Transaction Prices and Rents in Selected EU Countries; Final Report Prepared for the European Commission (DG Energy); European Commission: 2013. Available online: https://ec.europa.eu/energy/sites/ener/files/documents/20130619-energy_performance_certificates_ in_buildings.pdf (accessed on 6 April 2018).

2. Ramos, A.; Labandeira, X.; Löschel, A. Pro-environmental Housholds and Energy Efficiency in Spain. Environ. Resour. Econ. 2016, 63, 367-393. [CrossRef]

3. Eichholtz, P.; Kok, N.; Quigley, J.M. Doing well by doing good? Green office buildings. Am. Econ. Rev. 2010, 100, 2494-2511. [CrossRef]

4. Brounen, D.; Kok, N. On the economics of energy labels in the housing market. J. Environ. Econ. Manag. 2011, 62, 166-179. [CrossRef]

5. Fuerst, F.; McAllister, P.; Nanada, A.; Wyatt, P. Does energy efficiency matter to home-buyers? An investigation of EPC ratings and transaction prices in England. Energy Econ. 2015, 48, 145-156. [CrossRef]

6. Murphy, L. The influence of the Energy Performance Certificate: The Dutch case. Energy Policy 2014, 67, 664-672. [CrossRef]

7. Laine, L. Room for Improvement: The Impact of EPCs on Consumer Decision-Making. 2011. Available online: http://www.consumerfutures.org.uk (accessed on 12 April 2018).

8. Amecke, H. The impact of energy performance certificates: A survey of German home owners. Energy Policy 2012, 46, 4-14. [CrossRef]

9. Backhaus, J.; Tigchelaar, C.; de Best-Waldhober, M. Key Findings and Policy Recommendations to Improve Effectiveness of Energy Performance Certificates and the Energy Performance of Buildings Directive. 2011. Available online: https://www.ecn.nl/publications/BEE/0 (accessed on 5 April 2015).

10. Wahlström, M. Doing good but not that well? A dilemma for energy conserving homeowners. Energy Econ. 2015, 60, 197-205. [CrossRef]

11. Olaussen, J.O.; Oust, A.; Solstad, J.T. Energy Performance Certificates-Informing the informed or the indifferent? Energy Policy 2017, 111, 246-254. [CrossRef]

12. Directive 2002/91/Ec of The European Parliament and of The Council of 16 December 2002 on the Energy Performance of Buildings. Available online: https://eur-lex.europa.eu/LexUriServ/LexUriServ.do?uri=OJ:L: 2003:001:0065:0071:EN:PDF (accessed on 5 October 2018).

13. Directive 2010/31/Eu of The European Parliament and of the Council of 19 May 2010 on the Energy Performance of Buildings (Recast). Available online: https://eur-lex.europa.eu/LexUriServ/LexUriServ.do?uri=OJ:L:2010: 153:0013:0035:EN:PDF (accessed on 5 October 2018).

14. Isachsen, O.; Rode, W.; Grini, G. Implementation of the EPBD in Norway. Status in November 2010. Country Reports on EPBD Implementation, Concerted Action EPBD. 2011. Available online: https: //www.buildup.eu/en/practices/publications/implementation-epbd-norway-status-november-2010 (accessed on 2 April 2017). 
15. Gordon, M.J.; Shapiro, E. Capital equipment analysis: The required rate of profit. Manag. Sci. 1956, 3, 102-110. [CrossRef]

16. Energimerking.no. Karakterskalaen. Available online: https://www.energimerking.no/no/energimerkingbygg/om-energimerkesystemet-og-regelverket/karakterskalaen/ (accessed on 29 February 2016).

17. Energimerking.no. Energimerkestatistikk. Available online: https://www.energimerking.no/no/ energimerking-bygg/energimerkestatistikk/ (accessed on 29 February 2016).

18. Marmolejo-Duarte, C.; Chen, A. The evolution of energy efficiency impact on housing prices. An analysis for Metropolitan Barcelona. Revista de la Construcción 2019, 18, 156-166. [CrossRef]

19. Malpezzi, S. Hedonic pricing models: A selective and applied review. In Housing Economics and Public Policy; O'Sullivan, T., Gibb, K., Eds.; Blackwell Science: Oxford, UK, 2003; pp. 67-89.

20. Nordpoolgroup.com. Day-Ahead Prices. Available online: https://www.nordpoolgroup.com/Market-data1/ Dayahead/Area-Prices/ALL1/Yearly/?view=table/ (accessed on 29 February 2016).

21. NVE. no. Utvikling av Gjennomsnittlig Nettleie for Husholdninger. Available online: https://www.nve.no/reguleringsmyndigheten-for-energi-rme-marked-og-monopol/nettjenester/nettleie/ nettleiestatistikk/utvikling-av-gjennomsnittlig-nettleie-for-husholdninger-1993-dd/ (accessed on 29 February 2016).

22. Norges-bank.no. Rentestatistikk. Available online: https://www.norges-bank.no/tema/Statistikk/ Rentestatistikk/ (accessed on 29 February 2016).

23. Case, K.E.; Shiller, R.J. Prices of single family homes since 1970: New indexes for four cities. N. Engl. Econ. Rev. 1987, 45-56.

24. Case, K.E.; Shiller, R.J. The efficiency of the market for single-family homes. Am. Econ. Rev. 1989, 79, $125-137$.

25. Prais, S.J.; Winsten, C.B. Trend Estimators and Serial Correlation; Discussion Paper No. 383.; Cowles Commission Chicago: Chicago, IL, USA, 1954.

26. Fregonara, E.; Rolando, D.; Semeraro, P. Energy Performance Certificates in the Turin real estate market. J. Eur. Real Estate Res. 2017, 10, 149-169. [CrossRef]

27. Marmolejo-Duarte, C.; Chen, A. The Uneven Price Impact of Energy Efficiency Ratings on Housing Segments and Implications for Public Policy and Private Markets. Sustainability 2019, 11, 372. [CrossRef]

28. Marmolejo-Duarte, $C$. The incidence of the energy rating on residential values: An analysis for the multifamily market in Barcelona. Informes de la Construcción 2016, 68, 543. 